\title{
A report on injuries and illnesses among athletes and games officials during XII South Asian Games-2016, Shillong, India
}

\author{
Bhaskar Borgohain $^{1}{ }^{*}$, Cherry M. Tariang ${ }^{1}$, J. P. Darjee ${ }^{1}$, Arnest Marbaniang ${ }^{2}$, Ozing Komut ${ }^{3}$, \\ Gangarani Angom², Robert S. Marak ${ }^{4}$, Tashi G. Khonglah ${ }^{1}$, Rituparna Barooah ${ }^{5}$, \\ Emanual Momin ${ }^{6}$, Neilatuo U. Suokhrie ${ }^{7}$, Nebanshan Lyngdoh ${ }^{1}$, Badashisa Lyngdoh ${ }^{1}$, \\ Rinchin Dorjee ${ }^{8}$, Dhanjit Nath ${ }^{8}$, Mamuniya Thangkhiew ${ }^{1}$, Bidhan C. Sharma ${ }^{1}$, Rajith P. ${ }^{1}$
}

\author{
${ }^{1}$ Department of Orthopaedics, ${ }^{2}$ Department of Emergency, ${ }^{3}$ Department of General Surgery, ${ }^{5}$ Department of \\ Physiology, ${ }^{6}$ Department of ENT, ${ }^{7}$ Department of Community Medicine, ${ }^{8}$ Department of Cardiology, NEIGRIHMS, \\ Shillong, India \\ ${ }^{4}$ D\&MHO, East Khasi Hills, Government of Meghalaya, Shillong, India
}

Received: 15 June 2017

Accepted: 19 July 2017

\author{
*Correspondence: \\ Dr. Bhaskar Borgohain, \\ E-mail: bhaskarborg@gmail.com
}

Copyright: () the author(s), publisher and licensee Medip Academy. This is an open-access article distributed under the terms of the Creative Commons Attribution Non-Commercial License, which permits unrestricted non-commercial use, distribution, and reproduction in any medium, provided the original work is properly cited.

\begin{abstract}
Background: The $12^{\text {th }}$ South Asian Games (SAG) was held from February 5-16, 2016 in Guwahati and Shillong. International level mega-events bring people of different background to a single geographic location after extensive travel. Surveillance and measures for primary and secondary prevention of injuries and illnesses by the organizers and host country is highly desirable. There is no such previous published report on South Asian games. The study was conducted with the aim to analyse the medical arrangements and report injuries and illnesses in athletes and games officials during the South Asian Games-2016 at Shillong venue.

Methods: : It is a retrospective study from all daily records of injuries and illnesses reported to the principal referral hospital designated to treat all significant injuries and illnesses for games officials and athletes from all eight participating countries staying in Shillong.

Results: Eight major sports were conducted in Shillong that included Badminton, Boxing, Football, Judo, Taekwondo and Wushu. The average age of the injured athletes or ill officials combined was 27.5 years. Male to female ratio was approximately 7:3. There were a total of 65 injuries (59.6\%) out of 109 hospital visits including six dislocations involving the upper limbs, but only one athlete required hospitalization. Athletes from three major contact sports namely taekwondo, football and wushu dominated the injured list. A significant number of games officials had injuries and medical illnesses, some requiring hospitalization.

Conclusions: Thorough planning for befitting medical care arrangements is indispensable for successful conduct of any major sports event. Significant training, sensitization, preparedness, knowledge-based manpower and infrastructure are needed for adequate medical coverage before, during and after the schedule of any major sports events.
\end{abstract}

Keywords: Sports injuries, Illness, $12^{\text {th }}$ South Asian Games (SAG-2016), Preparedness

\section{INTRODUCTION}

The $12^{\text {th }}$ South Asian Games was held in Guwahati and Shillong from $5^{\text {th }}$ Feb, 2016 to $16-F e b-2016$ and was the biggest sporting extravaganza ever held in the North East
India and the first ever gender equal South Asian Games with men and women participation in all the sports. ${ }^{1}$ These twin capital cities of North-east India are separated by about 100 kilometer: Guwahati (Assam) and Shillong (Meghalaya), India. ${ }^{2,3}$ Famous for football talents, Shillong is a hill station and the capital of Meghalaya; 
geographically lying at $25.57^{\circ} \mathrm{N} 91.88^{\circ} \mathrm{E}$ with a small city population of 14300 that mostly speaks Khasi, English or Hindi. ${ }^{4}$ It is situated at an average altitude of 4,908 feet $(1,496 \mathrm{~m})$ above sea level having subtropical highland oceanic climate with average temperature between 7.2-16.8 Celsius during the month of February. ${ }^{4,5}$ There was participation of as many as eight south east Asian nations in this game that represents $21 \%$ of the world's total population., ${ }^{1,6}$ The organising and executive committees for the 12th South Asian Games have been formed by the Government of India in consultation with the Indian Olympic Association. These committees and games secretariat with its chief executive officers were responsible for planning, management and effective execution of the games. The main venues of the South Asian Games include Indira Gandhi athletic stadium and Jawaharlal Nehru stadium in Shillong. Out of the 23 sports held for both men and women (M\&W) include: handball, tennis, kho-kho, badminton, cycling, taekwondo, volleyball, wrestling, swimming, boxing, shooting and football. ${ }^{1,2,3,6}$

\section{METHODS}

Besides methods we will also have to discuss some relevant backdrop and our approach and manner of preparedness for medical coverage of the game for lucidity of description. It is a retrospective study conducted under the medical coordinator of the principal designated referral hospital (Author no.1) at Shillong. We traced all daily records of injuries and illnesses that were reported to the principal referral hospital designated to treat all significant injuries and illnesses for games officials and athletes staying in different locations in Shillong. Moreover on sight injuries are also incorporated in the final data.

We developed a simple injury and illness report form to record the following information: accreditation number, country of origin, sport and event, date, affected system and the main symptom(s), diagnosis, status (discharged/admitted/follow up needed). We treated all information with strict confidence, and anonymised our medical database at the end of the games.

The definition of injury and illness were taken from Engebretsen et al. ${ }^{7}$ Injuries and illness were defined as new (pre-existing or not fully recovered conditions were not recorded) or recurrent (athletes having successfully returned to full participation after previous condition) musculoskeletal complaints (including concussion) or medical illness diagnosed at training or competition regardless of the consequences of the athlete absence from competition or training. ${ }^{7}$ In cases where athletes sustained multiple injuries or affected multiple body parts, only the most severe diagnosis was documented. ${ }^{7}$

A list of prohibited drug was obtained from NADA (National Anti-Doping Agency) for the knowledge of the physicians involved in game related medical care. ${ }^{8}$
Days before the opening of the games, we invited the medical and nursing staff of the apex referral hospital to meetings covering the details of the study. In this meeting, we also started the distribution of the daily injury and illness report forms, as well as an instructional booklet detailing the dope control processes. Throughout the data collection, we frequently visited our team to encourage continuous medical reporting throughout the games ensuring high accuracy and response rate of our venue and hospital staff. After the successful conduct of the games all email communications received from games secretariat related to medical preparedness were revisited and a detail search in the web was done to confirm from available archives about the pre-requisites, schedules and impact of the XII SAG to understand the trend of injuries and illnesses of the athletes better.

Although as many as eight countries were participating, there was no games village at Shillong and athletes and officials were accommodated in designated hotels with deployment of law enforcement agency and food safety personnel for regular sampling for ensuring food safety. The state government controlled 108 GVK-EMRI ambulances were primarily used for all contingencies. The city civil hospital was designated the first reporting hospital and minor ailments are reported.

Procurements were done on urgent basis for essential medicines, sports injury related disposables, splints, ice boxes, spine boards, kinesio tapes etc to be kept only for the games. Medical manpower was identified to be posted exclusively for the medical care of athletes and officials of the game. A formal training session was conducted by medical, sports experts and anti-doping experts. On site disaster mock drills were performed in the respective venues by the medical teams. Separate entry registers were provided to record medical illnesses and injuries of the athletes and games officials with regular updates sent daily to the games secretariat. Formal contract was made with 24 hour pharmacy to ensure availability of all medicines. Separate area was designated in the referral hospital only for the athletes and games officials. Separate safe drinking water facility installed for this area. The dietary section of the apex hospital was instructed to follow high level of hygiene and provide bottled water for athletes and officials.

Emergency department doctors and nursing staff were adequately sensitized to new requirements of the rules of the games like correctly recording the accreditation card number of the athletes before initiating medication for documentation and billing to the games secretariat at a later date and adherence to the entire prohibited drug list for the athletes (e.g. steroids, diuretic frusemide, fluid or blood transfusion etc.). The final date-wise Game schedule (calendar) was kept in the control room and designated hospitals to anticipate injuries and illness for better preparedness. 
Special demand form were printed in duplicates for prescription and billing of drugs and pharmacy that can be sent to the central 24 hours pharmacy having contract with games secretariat to urgently obtain by medicine on loan basis.

\section{RESULTS}

Before we present results it may be pertinent to discuss the climatic condition and some aspects of the preparation for the game. The temperature of Shillong was 21 degree celsius (range 12-32) with average humidity of $75 \%$ (range $28-100 \%$ ) during this period. Held under the aegis of South Asian olympics council, the $12^{\text {th }}$ South Asian games had a total of 2,672 athletes completing over 23 sports in 228 events happening in two cities separated by about $100 \mathrm{~km}$. Participation of athletes and officials from various countries are depicted (Table 1, Figure 1and 2). It was the biggest sporting spectacle ever in the Northeastern part of the country. Significantly, there were an equal number of disciplines for men and women, the first time in the games history.

Eight major sports in four different locations were conducted in Shillong: archery (M\&W), badminton $(\mathrm{M} \& \mathrm{~W})$, boxing $(\mathrm{M} \& \mathrm{~W})$, football $(\mathrm{W})$, judo $(\mathrm{M} \& \mathrm{~W})$, table tennis $(\mathrm{M} \& \mathrm{~W})$, taekwondo $(\mathrm{M} \& \mathrm{~W})$, wrestling (Men) and wushu (M\&W). Basketball games were dropped at the last. Games secretariat had 16 functional areas. Arrangements were being made for ease of accreditation, arrival, departure, comfortable stay, security, medical facilities and transport arrangements, etc. The participation of athletes and officials from various countries is given below. Around 100 representatives of International media were to cover the event on the spot.

Table 1: Participation of athletes and officials from various countries in 12th SAG.

\begin{tabular}{|llllll|}
\hline Country & $\begin{array}{l}\text { Men - no. of } \\
\text { disciplines/ no. of } \\
\text { athletes }\end{array}$ & $\begin{array}{l}\text { Women - no. of } \\
\text { disciplines/no. of } \\
\text { athletes }\end{array}$ & $\begin{array}{l}\text { No. of Officials } \\
\text { (Men) }\end{array}$ & $\begin{array}{l}\text { No. of Officials } \\
\text { (Women) }\end{array}$ & Total \\
\hline Afghanistan & $16(102)$ & $10(49)$ & 61 & 2 & 214 \\
\hline Bangladesh & $22(223)$ & $18(147)$ & 99 & 10 & 479 \\
\hline Bhutan & $9(58)$ & $7(27)$ & 29 & 4 & 118 \\
\hline India & $23(276)$ & $23(245)$ & 114 & 68 & 703 \\
\hline Maldives & $9(72)$ & $9(79)$ & 38 & 19 & 208 \\
\hline Nepal & $22(190)$ & $23(191)$ & 90 & 25 & 485 \\
\hline Pakistan & $21(205)$ & $19(141)$ & 104 & 22 & 471 \\
\hline Sri Lanka & $23(251)$ & $23(226)$ & 687 & 164 & 651 \\
\hline Total & 1377 & 1105 & 851 & & 3333 \\
\hline Grand total & 2482 & & & & \\
\hline
\end{tabular}

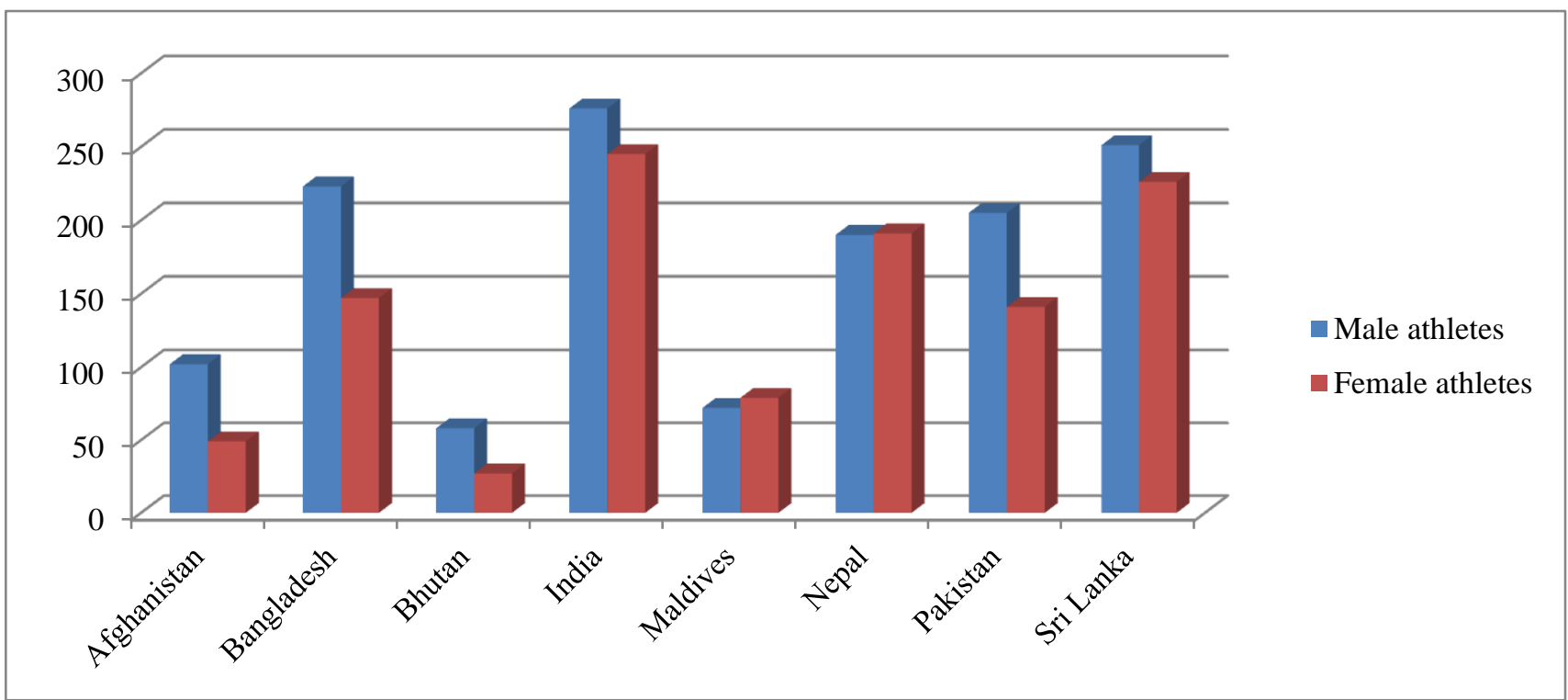

Figure 1: No. of participating athletes from different countries in 12th SAG. 


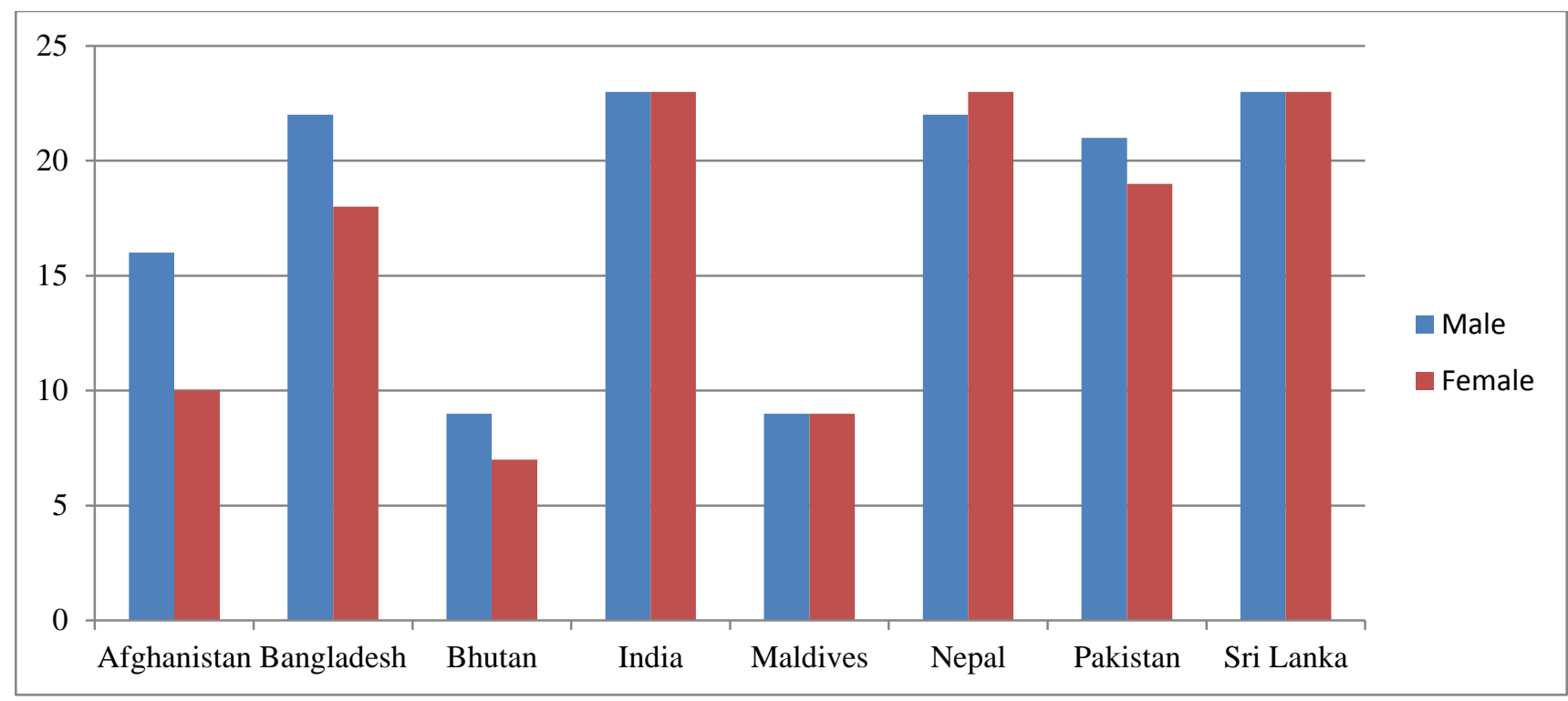

Figure 2: No. of sports event participated by athletes from different countries in 12th SAG.

The athletes and games officials started arriving ahead of the game dates to Shillong for practice ahead of the game. Their age ranged between 20-63 years (average 39.75 years). There were a total of 109 visits by 99 athletes and officials to the designated apex referral hospital, that included follow up for physiotherapy, cryotherapy, kinesio taping, dressing, stitch removal, blood report collection etc. The injured or ill cohort had male 69, female 30; in ratio of 7:3 (Figure 3). There were a total of 65 injuries $(59.6 \%)$ out of 109 hospital visits. The overall injury rate is $2.6 \%(65 / 2482)$. There were six cases of joint dislocation or subluxations involving the upper limbs (6/65) i.e. a high $9.2 \%$ dislocations among the participants.

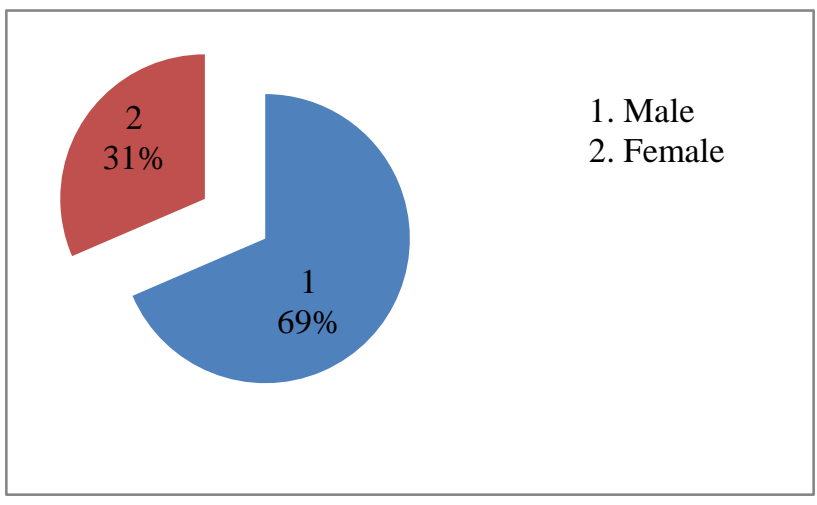

Figure 3: Gender distribution of injuries and illnesses during SAG-2012.

Among the eight types of sports played in Shillong venue the risk of an athlete being injured was the highest in taekwondo, football, and boxing due to their high contact and combat characteristic and the lowest in archery and badminton (Figure 4). There was a definite male preponderance in all injuries. Afghanistan, India and Nepal athletes topped the injured athlete list, but athletes from all countries had some injuries before (during practice) and during the games. Athletes from Afghanistan had maximum injuries (35/151) i.e. 23.3\% followed by Indian athletes $(19 / 521)$, i.e. $3.6 \%$ of their total athletes (Figure 5) respectively. Twenty out of 35 Afghan athletes (57\%) had musculoskeletal symptoms and the others had medical illnesses needing medical attention, but did not require hospitalization. Although a contact sport, wrestling had comparatively low incidence of injuries in our study. Although anticipated, there was no concussion injury during taekwondo in our study that could be potentially fatal if missed. Although injured athletes started reporting days before the schedule (possibly due to intense practice), maximum injuries were reported during the specific competition events involving football, badminton and wushu. As much as eighteen injuries (18/65) were reported on $10^{\text {th }}$ February from football, taekwondo and wushu venues. In 12 days a total of 101 hospital visits were recorded, i.e. rate of injuries or illnesses was about 8.4/day. Fortunately, majority of injuries and illnesses were minor in nature and did not prevent the injured from further participation.

The rate of medical illness was the highest in games officials rather than in the athletes. Acute febrile illness, infective hepatitis, gastrointestinal symptoms and exacerbation of pre-existing skin ailments topped the list of medical illnesses. Water born infection like acute gastroenteritis was noted among a few athletes and officials. Four games officials including two foreign officials and one CISF (Central industrial security force) security personnel required hospitalization during the game for medical illnesses: acute febrile illness, two cases of acute viral hepatitis and one chest pain with hypertension needing observation coronary unit. Two cases of acute viral hepatitis appear to be of faeco-oral origin which was in their incubation period before entering Shillong. The since these illnesses occurred 
much before the game began, the accreditation cards were not handed over or available at the time of admission for availing treatment entitlement free of cost (to be billed to the games secretariat) and special arrangements were needed to start treatment in such cases until such accreditation cards could be issued. The commanding officer of the CISF personnel was contacted to update recovery for planning his return journey.

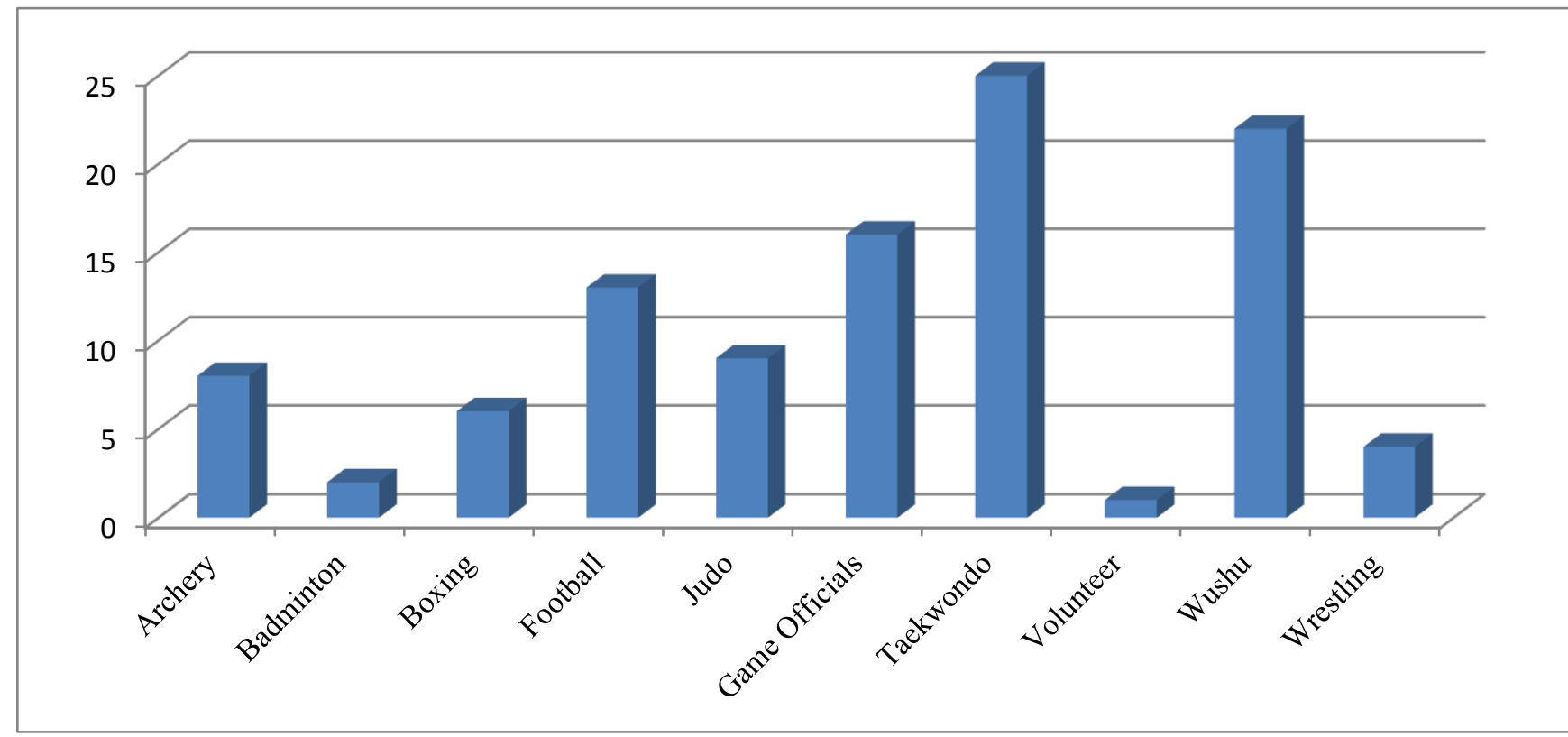

Figure 4: General Trend of significant injuries and illnesses among athletes \& officials of SAG-2016 at Shillong.

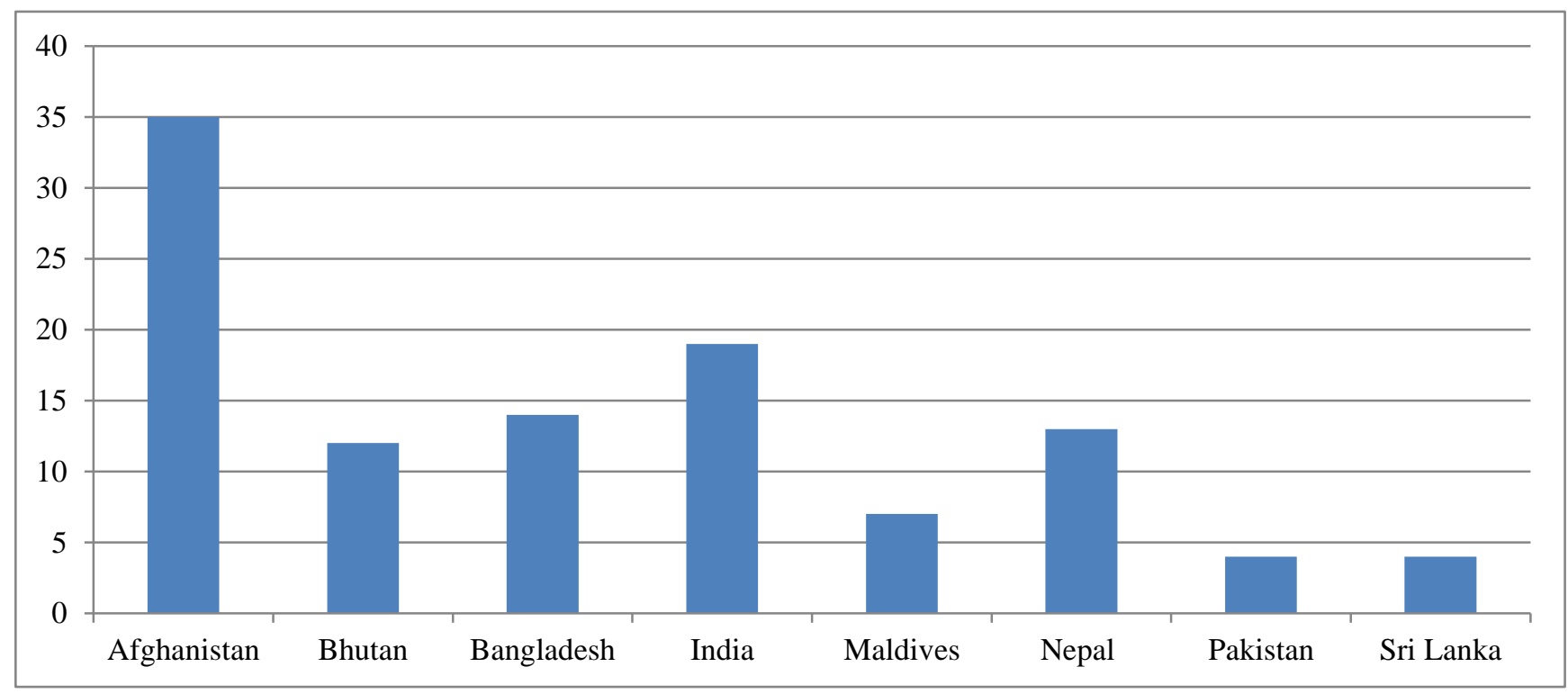

Figure 5: Country-wise Injury and illness profile among athletes \& officials of SAG-2016 at Shillong.

\section{DISCUSSION}

International level mega-events bring people of different background to a single geographic location after extensive travel and after crossing International borders to take part in sports in an unfamiliar region. The olympic movement medical code encourages all stakeholders to ensure sport safety and health of the athletes. It is therefore essential to have necessary plan and preparedness to consider prophylaxis against endemic diseases like malaria, sports injuries and all medical contingencies of the athletes and officials. This first such report on SAG may help understand the medical perspectives of major sports events involving large participation for better preparedness by all stakeholders.

A major limitation of our study is lack of data from Guwahati venue where most other events were held. Moreover minor injuries and self-treatment etc. are not included in the data. Nevertheless as many as eight major 
events were held in Shillong. As reported from other studies the rate of injury and illness were influenced by gender and type of sports. ${ }^{7,9}$ Unfortunately during SAG2016 there was no games village at Shillong venue since the preparation time for the game for the host country was just six months (the earlier host country who were to host the event, opted out). ${ }^{10}$ Successful conduct of the games is to be seen in the context of record time in which it was executed. It was barely six months ago when the two cities Guwahati and Shillong were finalized as venues. Games of this scale generally take at least two years to execute if not more. ${ }^{11}$

The athletes and officials were accommodated in different designated hotels with deployment of food safety inspectors for regular sampling for ensuring food safety to them. This made it difficult to provide centralized medical care. All hotel reception desk personnel were sensitized and given phone numbers of central medical and dope control room set up in one centrally located hotel. GVK-EMRI 108 ambulance was on standby mode for all medical contingencies. Prehospital care facilities were designated as the closest appropriate health facility. Police personnel would accompany the moving ambulance carrying persons from foreign countries for security reasons, since several terror groups have threatened to disrupt the game.

Sufficient numbers of disposable packs of ice bags (to be kept in ice containers), pain killer spray and rolls of kinesio taping were rather items frequently asked by the athletes during practice sessions and also during competition. This requires some training and expertise before the game begins especially on part on the venue team to reduce premium time loss in the playing arena. Food, water, comfort foods and beverages needs to be included in the budget and arranged beforehand accordingly for the medical team members, since the medical personnel cannot leave the venues until relived by the next team.

Ideally the host committee shall issue travel advisory to international athletes to adequately cover endemic diseases and undertake region specific chemoprophylaxis, vaccination etc. before travelling. ${ }^{12}$ Waterborne diseases prevention is another important aspect during sports mega events. ${ }^{13}$ Sport medicine is a new emerging specialty, with experimental techniques and treatments becoming increasingly common. There is a need to therefore employ evidence based medicine principles when evaluating treatments to ensure that only techniques with strong evidence for their use are employed. ${ }^{14}$ Future games organizers can improve data collection to develop injury and illness prevention measures to set regional standards. ${ }^{15}$

In summary, adequate medical facilities are important for successful conduct of any major sports event, however this may not be the top priority of the top officials unless top medical and dope control officials influence positively. Prophylaxis for the endemic diseases is to be considered. Our report is first such report on SAG that may help understand the medical perspectives of major sports events involving large participation for better preparedness by all stakeholders. The incidence of sports injuries and even the medical illnesses varied substantially among sports. Dope control protocols are unfamiliar to most health care workers. Future initiatives should include the development of preventive measures tailored for each specific sport and the continued focus among sport bodies involved in the SAG to institute and to further develop scientific injury and illness surveillance systems for reducing injuries and illnesses in the futures games. The knowledge gained from our study may help to appropriately inform injury prevention strategies to athlete population at risk. Significant training, sensitization, preparedness, knowledge-based manpower and infrastructure are needed for adequate medical coverage before, during after the schedule of any major sports events. Future games organizers can improve data collection to develop injury and illness prevention measures to set regional standards.

\section{ACKNOWLEDGEMENTS}

We would like to thank Dr P. S. Mohan Chandran, President, Indian Federation of Sports Medicine. New Delhi; Sri Y. Tsering, IAS, Principal Secretary Health, Govt. Of Meghalaya; Sri R. K. Sharma, CEO, SAG-2016, Shillong; Sri David Umdor, FA member (SAG-2016) and Venue administrator (NEIGRIHMS); Dr Aman War, Medical Director, SAG-2016, Shillong; Sri F. R. Kharkongor, IAS, Joint CEO, SAG-2016, Shillong; Dr Ashok Ahuja, Sports Medicine Consultant BCCI, IPL and CEO, ISSRA; Prof A. G. Ahangar, Former Director, NEIGRIHMS, Shillong; Prof A. C. Phukan, Former Medical Superintendent, NEIGRIHMS, Shillong; Dr S. Perumal, Expert, National AntiDoping Agency (NADA), India; Sri Harendra Dey: Procurement Officer, NEIGRIHMS; Sri Deepankar Choudhury, Coordinator, EMRI 108 Ambulance Services, Meghalaya; CMOs: Kevin Z. Donoghue, Kavita Jain, Anna J. Momin.; Prof. A. Mishra, HoD, Cardiology, NEIGRIHMS, Shillong; Prof C. Daniala, HoD, Radiology, NEIGRIHMS, Shillong; Medical team support group: SAG Venue, NEIGRIHMS, Shillong; Tridib Borah, Divakar Das (Physio), Megha Nandwani, Rydah Khonglah, Buru Kapa, N.Naku, Dibyajyoti Bora and Diana Marwein

Funding: No funding sources Conflict of interest: None declared

Ethical approval: The study was approved by CEO, SAG2016, Shillong venue

\section{REFERENCES}

1. Print release on 12th South Asian Games. Press Information Bureau, Government of India, Ministry of Youth Affairs and Sports. 01-February-2016 16:45 IST. Available at 
http://pib.nic.in/newsite/PrintRelease.aspx?relid=13 5975. Accessed on 5 January 2017.

2. 2016 South Asian Games" Wikipedia page. Available at https://en.wikipedia.org/wiki/2016_

South_Asian_Games. Accessed on 10 January 2017.

3. Competition Schedule - 12th South Asian Games, Guwahati \& Shillong. Available at https://web.archive.org/web/20160125171008/http:// www.southasiangames2016.com/CompetitionSched ule.aspx. Accessed on 5 January 2017.

4. Shillong. Wikipedia page. Available at https://en.wikipedia.org/wiki/Shillong. Accessed on 10 January 2017.

5. High \& Low Weather Summary for February 2016. Available at https://www.timeanddate.com/weather/ india/shillong/historic?month=2\&year=2016.

Accessed on 10 January 2017.

6. Print release on 12th South Asian Games. Press Information Bureau, Government of India, Ministry of Youth Affairs and Sports. Available at http://pib.nic.in/newsite/PrintRelease.aspx?relid=13 6108. Accessed on 5 January 2017.

7. Engebretsen L, Soligard T, Steffen K, Alonso JM, Aubry M, Budgett R, et al. Sports injuries and illnesses during the London Summer Olympic Games, 2012. Br J Sports Med. 2013;47(7):407-14.

8. WADA prohibited list of Drugs. Available at http://nada.nic.in/View/Downloads/writereaddata/w ada_2016_prohibited_list.pdfhttp://nada.nic.in/View /Prohibited.aspx. Accessed on 7 January 2017.

9. Ahamid MS, Puji A, Salleh Z, Jamalullail Z, Hussein KH. Patterns of Injuries and Illness Among Malaysian Athletes during the XVII Asian Games 2014. Sains Malaysiana. 2016;45(10):1531-6.
10. Bora S. Athletes rue absence of Games Village at venues. The telegraph, Saturday, February 13, 2016 Guwahati. Available at https://www.telegraphindia. com/1160213/jsp/northeast/story_68992.jsp.

Accessed on 17 February 2017.

11. Achievements/initiatives and success stories of the department of sports on completion of two years of NDA government". Department of Sports, Ministry of Youth Affairs \& Sports, Government of India 2016. Available at http://yas.nic.in/sites/default/ files/achievements-sports2016.PDF. Accessed on 12th February 2017.

12. Kary JM, Lavallee M. Travel medicine and the international athlete. Clin Sports Med. 2007;26(3):489-93.

13. Hadjichristodoulou C, Mouchtouri V, Vousoureli A, Konstantinidis A, Petrikos P, Velonakis E. et al. Waterborne diseases prevention: evaluation of inspection scoring system for water sites according to water microbiological tests during the Athens 2004 pre-Olympic and Olympic period. J Epidemiol Community Hlth. 2006;60(10):829-35.

14. Heron N, Malliaropoulos NG. International differences in sport medicine access and clinical management. MLTJ. 2012;2(4):248-52.

15. Llinás PJ, Serrano RF, Barrera LQ, Noguera JC, Cano JP. Sports injuries and ill-health episodes in the Cali 2013 World Games. BMJ Open Sport Exercise Med. 2016;2(1):e000072.

Cite this article as: Borgohain $\mathrm{B}$, Tariang CM, Darjee JP, Marbaniang A, Komut O, Angom G, et al. A report on injuries and illnesses among athletes and games officials during XII South Asian Games (SAG-2016), Shillong, India. Int J Res Orthop 2017;3:1031-7. 